\title{
Open
}

\section{Personal Care Savings Bonds: A New Way of Saving Towards Social Care in Later Life*}

\author{
Les Mayhew and David Smith \\ Faculty of Actuarial Science, Cass Business School, City University London, 106 Bunhill Row, \\ London EC1Y 8TZ, U.K. \\ E-mail: lesmayhew@googlemail.com
}

An ageing population ushers in a completely new era requiring society to find new solutions to funding social care and looking after older people. This is not a temporary issue that will go away and there are no quick economic fixes. In the U.K. it is estimated that the population aged 75+ will double from 5 million to 10 million by 2040. Financial building blocks are needed to pay for social care that will be sustained for decades and provide extra security for the individual. This paper proposes a new savings product called Personal Care Savings Bonds (PCSBs), which are designed to encourage saving for social care by providing extra money at the time of greatest financial need. PCSBs are likely to be attractive to older people who have only a basic pension and modest savings, but also to other age groups, as they not only attract interest but also pay prizes. Based on reasonable assumptions, the paper shows how the fund could build into a substantial investment worth $£ 70$ billion with regular monthly prize pay-outs. In concept they are somewhat similar to Premium Bonds, another U.K. personal savings product that has been successfully operating since 1956.

The Geneva Papers (2014) 39, 668-692. doi:10.1057/gpp.2014.30

Keywords: paying for social care; personal care bonds; care assessments; fund accrual; prize money; funeral costs

Article submitted 19 January 2014; accepted 28 July 2014; published online October 2014

The online version of this article is available Open Access

\section{Background}

The social care system in England has been subject to considerable previous scrutiny ${ }^{1}$ into its funding. Despite intense policy debate since, it remains the least understood and most contentious part of the welfare state, especially on the question of how it is paid for.

The system currently is, and looks likely to remain, a mix of public and privately funded care with support for those with least financial means. ${ }^{2}$ It is planned that the private sector will play a greater role both in the provision of care and in providing personal financial products to pay for care such as insurance.

\footnotetext{
*Personal Care Savings Bonds were launched at a meeting in the House of Lords hosted by ILC-UK in May 2013. This paper is an updated and extended version of the original paper and includes new material and subsequent research.

${ }^{1}$ E.g. The Royal Commission on Long Term Care (1999).

${ }^{2}$ Mayhew et al. (2010).
} 
On 11 February 2013, the Government of the United Kingdom announced the introduction of a reform to the social care system to prevent individuals from spending all their savings or being forced to sell their home during their lifetime to pay for care, which hitherto had been one of the most politically sensitive areas of social care policy. ${ }^{3}$

The reform includes a cap such that individuals will in the future only be liable for up to $£ 72,000$ of their care costs as announced in the March 2013 Budget and that these reforms would be introduced from 2016 , a year ahead of schedule. ${ }^{4}$ Currently, no cap exists, leaving many facing large bills, with almost one in five older people facing care costs of the magnitude of the cap.

In addition to the cap, there will be a new means-test threshold such that in the future, people will no longer need to be down to their last $£ 23,250$ before they get financial help. The report of the Commission on Funding of Care and Support, ${ }^{5}$ from where the threshold derives, recommended that it should be raised to $£ 100,000$. The Government initially set a figure of $£ 123,000$, but this was then reduced to $£ 118,000$ following the Budget in 2013.

Together, these reforms are forecast to cost the Exchequer $£ 1$ billion a year by the end of the next Parliament, beginning in 2015 , and will rise thereafter. ${ }^{6}$ The cost is expected to be met in part by extending the freeze on the Inheritance Tax threshold at $£ 325,000$, or up to $£ 650,000$ for couples, for three years from 2015 to 2016 . The remainder will be funded by technical adjustments to the National Insurance system.

Apart from any net expenditure incurred by the reforms, no extra money is promised to fund the growing funding gap in social care. Individuals will therefore continue to be responsible for a large proportion of their care costs, as they are currently, except for those with least means.

As a recent parliamentary select committee report has noted, "The proposals are primarily concerned with redistributing the costs of care. They do not bring extra funding into the system to tackle the current funding crisis, ... or address the problem of expanding need in the coming decades". ${ }^{7}$

This is important because an ageing population ushers in a completely new era, requiring society to find new solutions to the funding of social care and looking after older people. ${ }^{8}$

Nor is this a temporary issue that will go away and there are no quick economic fixes. The Office of National Statistics (ONS) population projections, for example, estimate that the population aged 75+ will double from 5 million to 10 million by 2040 .

Clearly, financial building blocks will be needed to pay for social care that will be sustainable for decades to come and provide extra security for the individual. This paper proposes one such financial mechanism, which we call Personal Care Savings Bonds (PCSBs).

\footnotetext{
${ }^{3}$ www.gov.uk/government/news/landmark-reform-to-help-elderly-with-care-costs.

${ }^{4}$ Originally the Government announced the cap as $£ 75,000$ but this was reduced to $£ 72,000$ in the March 2013 Budget, most likely as an adjustment for inflation.

${ }^{5}$ Commission on Funding of Care and Support (2011). The report of the Commission is known as the "Dilnot report" after its author Andrew Dilnot.

${ }^{6}$ Department of Health (2013).

${ }^{7}$ House of Lords (2013, p. 62).

${ }^{8}$ Karlsson et al. (2006, 2007).
} 
670

This paper sets out the arguments for such a product, to whom it is primarily aimed and how it would fit with the reforms currently under way. It provides financial estimates of the contribution it could make to social care, and finally offers some practical suggestions for its implementation.

\section{Role of private finance}

One of the hoped for changes resulting from the Dilnot report is that it will allow insurance products designed to meet long-term care costs to become more affordable and encourage the private sector to engage in this potentially lucrative market.

Although this may be so, insurance will not be attractive or suitable for everybody and other products will be needed for people with different means and/or attitudes towards risk. Mayhew et al. ${ }^{2}$ described some of these products in their paper on the role of the private sector in paying for long-term care.

These included products such as disability-linked annuities, which would sit alongside other products such as equity release and immediate needs annuities, which are often funded through the sale of the home. Such products seem well suited to the U.K. due to so much personal wealth being tied up in housing assets and pensions.

Although such products are perfectly reasonable for those with assets and moderately sized pensions or large personal savings, for large numbers of older people, these are never going to be viable options and they will continue to fall back on the state for financial help.

There are also concerns that even with the introduction of a cap on care costs, insurance products will not be appropriate, affordable, or even available to everyone under a capped cost model. In addition, pension pots would need to be substantial for enhanced disabilitylinked annuities and similar products to be attractive to pension savers.

Given the growing funding gap in public provision and concerns about personal finances, it is our view that more needs to be done to bring new money into the social care system. Based on recent decisions and the demise of previous reform attempts, we do not believe that the state will want or be able to provide ever-increasing support without a fundamental redirection of government spending priorities. ${ }^{9}$

In other words, social care is an area of activity in which the cost is always going to be a split responsibility between the taxpayer and the individual. If spending by the state and by the individual does not keep pace with need, then the quality and availability of care will suffer unless there are better mechanisms to help people support themselves.

It is true that efficiency improvements in the delivery of care may assist alongside reforms aimed at better integrating health and social care, but success is not guaranteed. It can therefore be argued that the longer-term question is how to bring new money into the care system, either to replace state spending or, preferably, as additional spending.

It is important to stress that there are no perfect solutions. A pay-as-you-go system for funding social care, along similar lines to the NHS, would involve a combination

\footnotetext{
${ }^{9}$ Mayhew and Rickayzen (2012).
} 
of higher taxes, more borrowing and/or redirecting public finances from other priority areas.

In summary, a way has to be found to make it easier and more attractive for people to save for their social care needs in a way that builds up over decades and gives people a personal stake. In what follows, the next section sets out the case for PCSBs; the subsequent section describes the financial principles behind PCSBs; the next section analyses the market for PCSBs, including how the fund might be used and invested; the penultimate section considers practical issues of implementation and the final section concludes.

\section{Personal care savings bonds}

PCSBs are designed to encourage saving for social care by providing extra money at the time of greatest financial need. PCSBs can be bought by anybody but are primarily designed to provide extra financial support to older people who have only a basic pension, and modest savings and assets.

PCSBs are likely to be attractive to a range of people throughout their adult lives because they not only attract interest but also pay prizes. Purchasers will therefore include spontaneous purchasers as well as regular savers, but also people who are not regular savers who like to gamble. ${ }^{10}$

Such products have been described as prize linked savings (PLS) accounts. ${ }^{11}$ In addition to offering a fixed interest return, PLS accounts offer depositors the chance to win a specified (and potentially large) amount that is a function of deposit amounts.

Although PCSBs will not cover everybody's care costs, their total value is likely to be substantial and greater than the value of any insurance market for most other long-term care products. There is no equivalent product currently on the market at present since the concept is neither a pure lottery nor a conventional savings account but a combination of both.

The nearest equivalent is the Premium Bond, which was first introduced in 1956 and is still hugely popular with U.K. savers. ${ }^{12}$ However, there are other popular fund-raising lottery-style schemes both in the U.K. and elsewhere ${ }^{13}$ but, unlike Premium Bonds, the stake is forfeited in these cases.

Frequently, lotteries are used in lieu of voluntary contributions by private charities and governments when taxes are not feasible, and the same argument applies to Premium Bonds. As the investment in Premium Bonds is redeemable, comparing PCSBs with Premium Bonds rather than lotteries is therefore more useful.

National Savings and Investments (NS\&I) are responsible for the administration of Premium Bonds. All the money invested with NS\&I is backed by the Government, with no overall limit on how much is guaranteed, and this may be seen as an advantage in comparison with some other forms of saving.

With around 23 million depositors, the total value of Premium Bonds currently stands at $£ 43$ billion. They pay around 1.8 million prizes a month to a value of around $£ 50$ million,

${ }^{10}$ Tufano et al. (2008).

${ }^{11}$ For reviews, see Tufano et al. (2008) or Kearney et al. (2010).

12 Tufano (2008).

${ }^{13}$ For example, for history, see Douglas (2000). 
672

with prizes ranging in size from $£ 25$ to a single maximum prize of $£ 1$ million; however, 89 per cent of the prize fund is paid out in prizes of up to $£ 100$ (source: personal communication with NS\&I).

Premium Bond prizes are tax free and equivalent to an annual return on investment of about 1.5 per cent. However, the chances of winning will obviously vary depending on the prize structure, with the probability of winning a particular prize reducing as the prize value increases.

Premium Bonds tend to be bought by two types of saver: children, who receive them as gifts from relatives, and regular savers, who tend to be aged 30 and above. They are not therefore normally regarded as an alternative to or in competition with, say, the national lottery.

Premium Bonds remain in perpetuity, although a disadvantage is that their value may be eroded by inflation over time. Nevertheless, it can be argued that the earlier they are purchased, the more likely it is that a prize will be claimed sometime in the future.

There are, however, two critical differences between PCSBs and Premium Bonds. The first is that, unlike Premium Bonds, PCSBs attract a small rate of interest, in addition to a prize element, which builds up over time. The second is that PCSBs will only be cashable on passing an assessment for social care or on the death of the person, and therefore funds are ring-fenced until such time as they are needed.

For this reason, and given the similarities between Premium Bonds and PCSBs, it would make sense if this new savings vehicle were also to be administered by NS\&I, though we have no firm views on this. We return to this issue and other practical aspects such as the sale and distribution of PCSBs in the section "Practical considerations".

Currently there is a $£ 30 \mathrm{k}$ limit on the amount that can be invested in Premium Bonds. Something similar could be envisaged in the case of PCSBs to protect the fund from speculators, although there would be no upper limit on the fund itself. This could take the form of annual limits on purchases as already applies, for example, to ISAs ${ }^{14}$ for broadly similar reasons.

However, these are generally issues for further consideration. One suggestion is to link the maximum deposits to the Dilnot cap such that accumulated investments of a certain percentage above the cap (currently £72,000) would be liable to taxation in the normal way.

\section{How PCSBs work}

PCSBs work as follows:

- Each bond has a nominal value assumed to be $£ 1$ and is entered into a monthly prize draw; prize winners are individual bond holders who can elect to receive the money or re-invest it in more bonds, thus increasing their personal fund.

- Bond values, both the prize element and accumulated value, will be tax free. PCSBs will normally be purchased out of taxed income, unlike personal pensions, though similar to

\footnotetext{
${ }^{14}$ Since they were first introduced in 1999, ISAs (independent savings accounts) have gained in popularity as a tax-free money saving option. Following the 2014 Budget, every resident of the U.K. will now be allowed to save up to $£ 15,000$ in stocks and shares or cash each financial year with the New ISA (NISA) instead.
} 
insurance products, Premium Bonds and lottery tickets. They would be purchasable over the Internet, by standing order, and from local post offices and/or shops.

- Cash can only be withdrawn from deposits on being assessed as needing social care or on death. This means that the chance of winning a prize would increase with age as long as an individual's fund accumulated in line with the total fund, and would reach a maximum value at the point of needing care or at the point of death.

- It follows that the longer a person lives without triggering social care, the larger the fund will be when it is required. In an example given in the Appendix, a person aged 90 would be up to 162 times more likely to win a prize than an 18-year-old assuming they saved regularly.

- For those who die before triggering a social care assessment, the value of the accumulated fund would transfer into a person's inheritance. This addresses one of the perceived problems of insurance for long-term care in which prospective policyholders may be concerned that they will not receive a benefit due to small print in the policy. With PCSBs, even if they do not receive a payment for care, their estate will get the benefit.

- In some cases bond values on death could be used to pay funeral costs, replacing some public expenditure that would have been incurred under the Social Fund. This would represent a small but useful saving on welfare expenditure ${ }^{15}$ and would provide an inexpensive form of funeral insurance for people who would not usually buy these products.

- Encashed bonds could be used in different ways by investors, assuming a social care need is triggered and the fund redeemed. Much depends on individual circumstances, and some examples are given later in the section "Who are PCSBs aimed at?".

The fund itself would build up over a period of time, and we provide an illustrative example in the section "Financial principles of PCSBs". Just as it took Premium Bonds several decades to build into a steady state, so it will take several decades for the fund to mature, and hence it is not an immediate solution to the funding gap but rather a foundation stone for a more diversified system of funding in future.

We do not regard the length of time for the fund to mature as a problem since demographic ageing is a long-term issue and most projections of life expectancy suggest that ageing is set to increase up to the end of the century, and hence the demand for social care is bound to continue its increase.

However, the fund is structured such that the prize money and benefits withdrawal could begin in year one, though clearly the initial value of the withdrawal benefits would not be nearly as high as when the fund has matured, and therefore expectations in the first years of what it would achieve would need to be managed carefully.

Indeed, it may be necessary for the Government to subsidise the early prize fund to make sure that it is attractive enough to get initial investors to purchase the bonds, though this amount could be slowly repaid over a period.

${ }^{15}$ Payments from the Social Fund can be made to claimants of means-tested benefits and tax credits to help meet the costs of a funeral. Payments are made from the regulated Social Fund and, as such, are not limited by budgetary constraints. Over 38,000 payments were made in Great Britain in 2011-2012, at a total cost of $£ 47$ million. 
674

\section{Treatment of bonds in means testing}

Currently, for a person to receive public support, all assets and income must pass a means test. Under present arrangements, the accumulated value of bond holdings would count towards assets and might lead to a reduced entitlement for help in paying for social care.

Based on the current means-testing formula, for example, a weekly income of $£ 1$ is imputed for each $£ 250$ of assets over the lower limit that a person is allowed to retain (due to be $£ 17,000$ in the reformed system), so that a saver could lose $£ 208$ of their investment for every $£ 1,000$ pounds worth of bonds above this amount.

Our clear preference would be for the benefits to be exempt, though clearly there would be very little reduction in public expenditure as a result. However, by making them exempt there would be more incentive for people with modest means to save, thereby bringing new money into the system.

It is also important that these bonds are exempt from any entitlement to welfare benefits before the point of needing care, and even before retirement. Therefore, for example, they would need to be exempt from the means-tested elements of Universal Credit ${ }^{16}$ that is currently being introduced. Otherwise, bond holders could have welfare benefits they need withheld because they have money in bonds that they cannot touch.

Since local care tariffs represent basic entitlement to care against which individuals are means tested, we would prefer that the additional money provided by bonds be part of a person's personal budget to buy higher-quality care if they so wished, although clearly there are arguments both ways.

Under present means-testing arrangements, the following cases may be identified:

1. A person dies without triggering care. The value of the fund would pass to their estate and might be subject to inheritance tax. For most people inheritance tax would not be applicable, while for the very poor the benefits on death may cover funeral costs that would have been paid by the state otherwise.

2. A person is assessed as needing care, but their accumulated assets including the benefits received from the bonds are below the lower means-testing threshold. They would have all their care paid for in the normal way by the state and the fund could be used, for example, to purchase additional care of services if they so wished (e.g. as part of a personal budget).

3. A person is assessed as needing care, but their combined assets are between the lower and upper asset threshold for means-testing purposes. Depending on their income they would have to pay a proportion of their care costs. If PCSBs were included in the asset test, there would clearly be a saving in public expenditure but not so otherwise.

4. A person is assessed as needing care, but their combined assets including the fund value put them above the upper asset threshold. They would receive no state help initially and thus there would be no immediate saving to public expenditure but they would keep all their investment. If their assets fell below the upper threshold after a period in care, then they might be entitled to some state help later. The cost to the state is therefore deferred and reduced assuming that the total period in care is the same.

\footnotetext{
${ }^{16}$ Universal Credit is a new single payment for people who are looking for work or on a low income which will simplify the existing benefits system by bringing together a range of working-age benefits into a single payment.
} 
5. A person is assessed as needing care and, even without the fund, their assets and income are such that they would not qualify for state help. In this scenario there may be no savings to the state, as even without the bonds the state would not have paid for their care. The main beneficiaries in this case are the people who will inherit their estate, as it will be larger than would have been the case without the fund. The state may benefit in the case of wealthy savers due to higher inheritance tax.

The financial incentives to purchase bonds may therefore differ by individual and, for most people, the category into which they will eventually fall could be difficult to predict from the outset. A key factor is likely to be how people perceive the purpose of the bond before purchasing it.

If people see it purely as a way of winning prizes, then the admissibility of assets will matter less. If instead people see this as primarily a way to save for their future social care, then the means-testing issue is likely to be an important deterrent factor in terms of their purchasing behaviour.

In summary, if the aim is to bring more new money into the care system, then how PCSBs are treated for means testing purposes becomes a strategic issue. In our view the wider care economy will benefit more if new money becomes available due to keeping PCSBs exempt.

\section{Financial principles of PCSBs}

The principles underpinning PCSBs are standard for this kind of product, namely, that once the fund has reached its stable value, the value of new deposits plus the interest earned on existing deposits should equal the outgo. In this case the outgo for a given period consists of prize money plus benefit payments.

Some prize money would be withheld to pay for administration costs and the amount of prize money could be varied, as with Premium Bonds, to ensure that the fund is able to meet its obligations.

The following example shows how the fund would operate once it has reached maturity (i.e. has reached a steady state), along with the build-up in deposits and withdrawals from inception. This illustration makes the following assumptions, although these can be changed as required.

- Mortality rates are based on the combined male and female life tables for England and Wales in 2009. An average of two years before death is spent in a care home, and one in five people is likely to need care (these assumptions can be varied ${ }^{17,18}$ ).

- It is further assumed that prize money is not re-invested in buying more bonds, although this is an option that, if widely exercised, would result in the fund growing even faster.

\footnotetext{
${ }^{17}$ Rickayzen (2007) estimates that there is a 25 per cent probability of a male aged 65 entering a care home and a 35 per cent probability for a woman. Our model starts at age 18 and hence, we have lowered the probability to 20 per cent in both cases to reflect the earlier start age in this illustration (see also Rickayzen and Walsh, 2002).

${ }^{18}$ A recent report by the Institute and Faculty of Actuaries (2014) assumes that 75 per cent of those entering a care home will live for at least 6 months, 50 per cent will live for at least 15 months, and 25 per cent will live for at least 36 months.
} 
676

- We assume constant mortality rates over the projection period. Since life expectancy is increasing, the results are possibly slightly conservative because people will have longer lives over which to save than we have allowed for.

- For ease of calculation, it is assumed that all bonds that are redeemed are redeemed halfway through the year.

Table 1 shows the other assumptions used: Overall the real long-term rate of return is assumed to be 3 per cent, which is split 1 per cent in prize money and 2 per cent investment return. It is assumed that 25 per cent of the adult population purchase bonds at any point in time and that they do so at a rate of 100 bonds per person per year (or roughly two per week).

To allow for easy interpretation over the long projection period, we are assuming no inflation (i.e. all values are kept in real terms; see Appendix). Under these assumptions the total value of the fund would attain a maximum value, once it had fully accrued, of $£ 69.6$ billion. This would take around 70 years from start to finish. Note that take-up of half the assumed rate would still lead to a fund worth $£ 35$ billion.

For this example, we assume that 20 per cent of investors would trigger care before they died. Varying this assumption has very little effect on the value of the fund, all other assumptions staying the same. For example, if 50 per cent triggered care, the size of the fund on maturity would only be around $£ 1$ billion less.

However, how the trigger point is determined will affect the amount taken in either care benefits while a person is still alive or the amount in death benefits, that is, to a person's estate. This balance is of critical importance in terms of how the fund will operate and support individuals in their care.

Thus, a low threshold would result in money being released earlier. It could be argued that this would provide resources before care needs become critical and thus may have a protective effect by preventing care needs from escalating unduly (see also the section "Practical considerations").

There is also a balance to be struck between the interest rate on deposits and prize money. The prospect of a large prize clearly draws people in, but it reduces the amount of money available in care and death benefits.

Note that the fund value in this example is larger than the current fund value of Premium Bonds ( $£ 43$ billion) by some margin. This is despite the fact that we assume about 12.6 million people purchase PCSBs, whereas there are 23 million holders of Premium Bonds.

The differences in fund size are partly a result of the fact that PCSBs earn interest and cannot be drawn down until the point of need, but in other respects it can be seen that these assumptions are quite conservative in terms of take-up relative to Premium Bonds.

Table 1 Assumptions used in illustrative example

\begin{tabular}{ll}
\hline Variable & Parameters \\
\hline Real investment return & $3 \%$ p.a. \\
Equivalent rate of interest for prize pool & $1 \%$ p.a. \\
Interest for investment return & $2 \%$ p.a. \\
Assumed bonds bought per person per year & $£ 100$ \\
Take-up & $25 \%$ \\
$\%$ of people who need care & $20 \%$ \\
\hline
\end{tabular}


However, it should be noted that we also assume regular purchase of these long-term care bonds, which may not be the case with Premium Bonds, and therefore, we return to this point later, drawing on information on observed purchasing behaviour.

Figure 1 shows the steady-state position of the fund by the age of saver. The assumed start age in this chart is 18 years; however, this is arbitrary (the minimum age, for example, for Premium Bonds or a lottery ticket is 16).

A second, smaller curve shows the annual value of withdrawals for comparison purposes. These are payments to people triggered on assessment of needing care or who die first and reach a peak between age 85 and 90 .

The aggregate fund, when separated by age, attains its maximum value at age 75 , after which it starts to decline as people enter care or die. If we look at individual holdings for individuals who are alive and not in care, then at age 75 the average fund is worth $£ 11 \mathrm{k}$ and continues to increase, reaching $£ 14 \mathrm{k}$ at age 85 and $£ 18 \mathrm{k}$ at age 95 based on our assumptions.

It can be argued that the assumed rate of return is too high given the state of the economy with interest rates at a historically low point. This does not mean that they will always remain at this rate, and interest rates will be expected to climb in due course, but even if the real interest were set at zero, it would have the effect of protecting the real value of individual holdings.

The following are two examples. First, if the real rate of return is 2.5 per cent, which is split 1.5 per cent fund retention and 1 per cent distributed as prize money, the long-term value of the fund would be $£ 60.4$ billion and the annual value of prize money $£ 606$ million. Second, if the real rate of return is 1.5 per cent, which is split 1 per cent fund retention and 0.5 per cent distributed as prize money, the value of the fund would be $£ 52.9$ billion and the annual prize money $£ 266$ million.

As previously noted, the impact of this money on the quality of care received by the person and/or the savings for the state depend on how the assets are assessed when determining whose care costs are covered by the state and how the benefits can be spent.

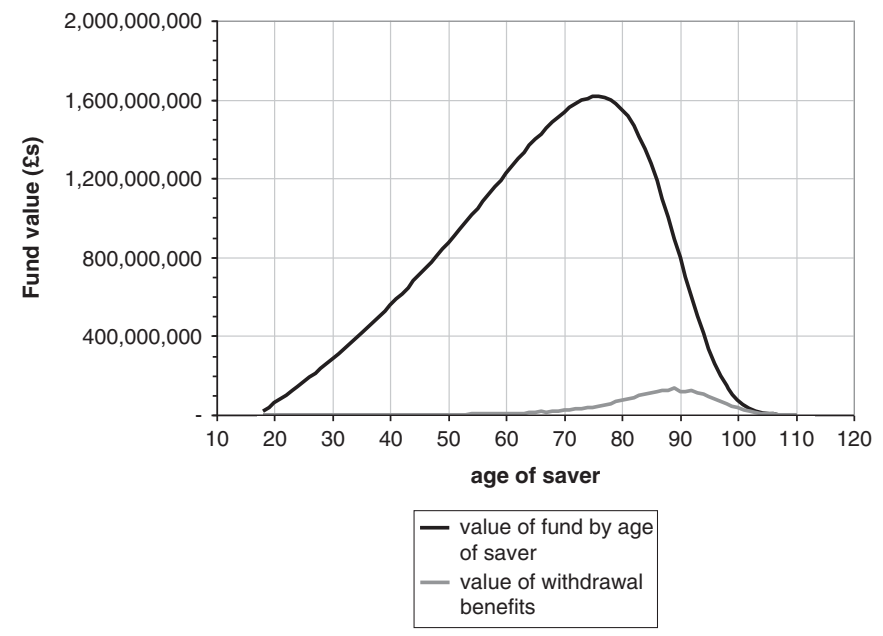

Figure 1. Steady-state value of fund and annual value of withdrawals due to payments on needing care, by age of saver. 
It is clear that these funds would be insufficient to pay the full costs of residential care, but they would be a significant contribution in the case of domiciliary care and reduce other financial pressures on individuals and their families at their time of greatest need. The extra money could be used, for example, to purchase higher-quality care or additional services as required.

To reach these values we have assumed a steady inflow of bond purchases and return on investment. The build-up phase is shown in Figure 2, in which the return on the fund equals annual purchases (assumed to be constant) plus the return on the fund.

The total outgo by contrast is shown in Figure 3. This has two elements-prize money and benefits. When added together to give total outgo, the amount is less than the total income up to maturity in approximately 70 years' time, from when inflow and outgo are in balance.

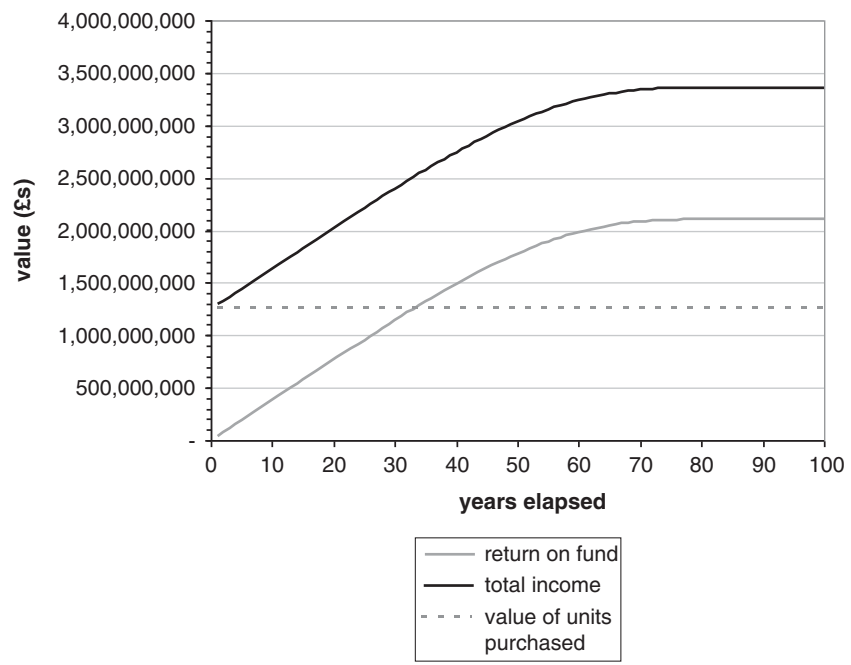

Figure 2. Cumulative income from start-up to steady state.

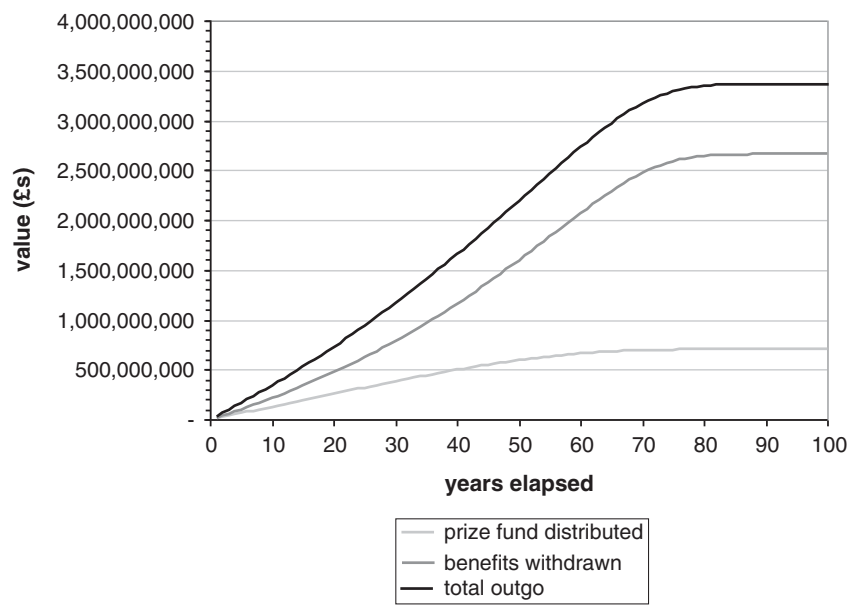

Figure 3. Cumulative outgo from start-up to steady state. 
As is the nature of these types of product, the accumulated individual sizes will be quite modest in size in the early years (e.g. a 65-year-old bond purchaser will only accumulate around $£ 1,100$ after 10 years if they purchased at the assumed rate). This is inevitable with any new scheme and therefore the full impact and benefits accruing need to be measured over decades.

\section{Who are PCSBs aimed at?}

We have assumed that any adult aged $18+$ could buy a bond, although this could be varied. Based on the experience of Premium Bonds, PCSBs should be broadly popular, but, as with lottery tickets, they are also likely to be attractive to people on lower incomes.

Research on lotteries, mainly in the U.S., confirms that poorer people spend a larger fraction of their income on gambling than the well-to-do and that they tend to do so by reducing other non-gambling expenditures. ${ }^{19}$

This suggests that national lottery sales in the U.K. would not be affected unduly by the introduction of PCSBs. In addition, the products differ markedly from each other and purchasers will be motivated by different reasons, but this statement may need to be tested in further research.

To give an example, it would be highly unlikely for a financial advisor to recommend that a person with a reasonable amount of wealth should buy lottery tickets with their savings, but they may well recommend the purchase of PCSBs as a compromise because they are safe and secure and the stake is not lost.

However, our financial modelling also requires that the market include people with a wide age range and income. A key question, for example, is whether younger adults would buy PCSBs in quantity. The example provided is based on $2 / 3$ interest and $1 / 3$ prize money, which may or may not be optimal for appealing to younger purchasers.

Younger adults are more likely to be attracted by the prize element rather than the building up of a fund, and their purchasing behaviour will reflect this. Hence, it will be important to get the balance right on the distribution of the prize fund, between fewer people winning but with larger prizes, more prizes but of lower amounts, or fewer total prizes but a higher investment return on the fund.

To some extent we already know some of the answers to this question based on current Premium Bond purchasing behaviour, which shows a very similar age distribution to that shown in Figure 1. Using NS\&I data, we found that 25 per cent of the population aged 18 to 36 buy Premium Bonds as compared with 50 per cent of the population aged $37+$.

We found that bond holdings increased with age but peaked earlier than in our model at around age 65. This is unsurprising, as retired bond holders tend to spend down their savings from retirement age. For PCSBs, holdings will peak at older ages since their draw-down will be triggered by care needs rather than retirement.

The data also show that the average period for which a Premium Bond is held is estimated to be 13 years, which is a relatively long time, but shorter than would need to be the case for PCSBs, which is why the extra incentive of the interest-bearing component is important.

\footnotetext{
${ }^{19}$ Laitner (1999); Kearney (2005).
} 
680

Additionally, bond purchases at younger ages tend to be individually large but lumpier as opposed to small steady purchases. Lumpier purchases comprise those gifted by relatives or as disbursements from deceased estates, but the overall effect leads roughly to the same agerelated holding pattern.

If the fund is to grow quickly, we believe that multiple deposits of lumpier sums should generally be encouraged because this opens up PCSBs to other types of investor, providing there are limits to prevent PCSBs being exploited as a tax shelter and therefore, a combination of steady and lumpier purchase would be ideal.

Other examples of how lump sums might arise include pensioners at the point of taking their pension or who downsize their home to a smaller property. They could be incentivised to buy PCSBs using special offers of the kind that say "buy ten and get one free" if they invest over a certain amount.

Other inducements could be considered. These could take several forms such as bonuses for people who had saved regularly over a number of years, introductory interest rate offers, higher interest rates for large depositors, or vouchers offering reductions among participating care providers in the scheme.

In summary, we can say that the purchasing profile of current Premium Bond holders broadly fits with our assumptions, but in order for the fund to grow quickly, purchasing behaviour may require modification using marketing strategies that are attractive to steady investors but are also havens for cash-windfalls.

\section{Identifying the potential market}

We have seen that PCSBs can be bought by anyone, including those who would not ordinarily save for their care or have the resources to pay for it. Intuitively these include subgroups with modest savings, who do or do not own their own homes but have only modest retirement incomes.

There are different ways of quantifying these groups. Previous work segmented the older population according to the notional number of years of residential or nursing care that could be afforded based on their income and assets combined.

This research found that without housing equity, over 80 per cent of people aged $65+$ would not be able to afford residential long-term care for more than a year, but with housing equity included this fell to around 14 per cent.

Many home owners, however, would not include the value of their home for paying for care, suggesting that the PCSB market could encapsulate more groups than previously supposed if they were marketed in the right way.

A more precise feel for the groups we are referring to is provided in Figure 4, which is a contour map of wealth and assets in the 65+ population, based on ELSA (English Longitudinal Study of Ageing). It shows that wealth is essentially bimodal according to whether a person has housing equity or not.

These two categories are represented by A and B in Figure 4. Both A and B have similar annual incomes, but the people in group B are chiefly those without housing assets. It can hence be argued that both A and B will be a significant part of the PCSB purchaser mix, which will be defined by their low income rather than their wealth.

The solid line shown in Figure 4 is the proposed boundary for eligibility for public support based on the proposed extended means-testing arrangements. Based on Figure 4, we found 


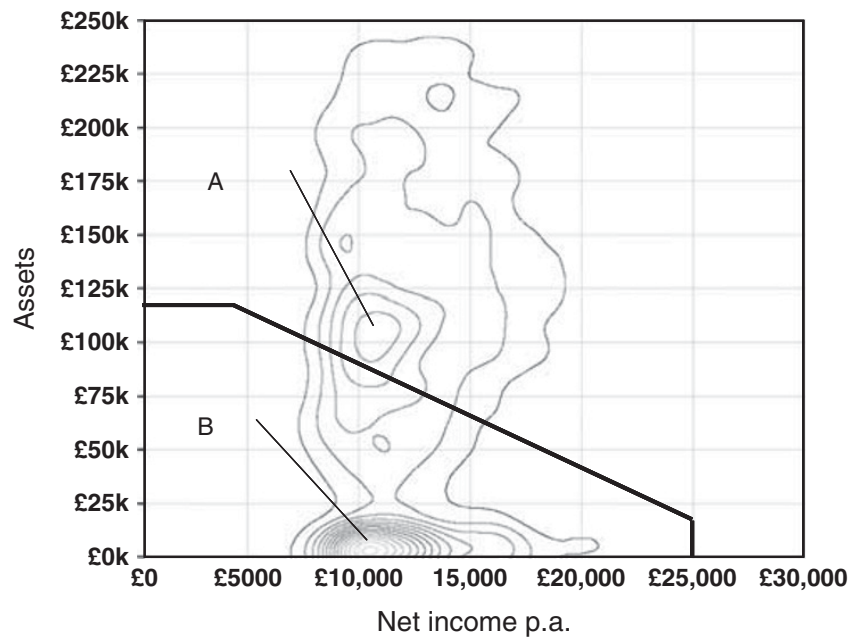

Figure 4. Contour map showing the distribution of assets and wealth in the older population (Source: $\operatorname{ELSA}^{20}$ ). The solid line represents the proposed new means-testing threshold for people with assets of up to $£ 118 \mathrm{k}$ and a lower threshold of $£ 17 \mathrm{k}$ assuming annual care costs of $£ 25 \mathrm{k}$.

that around 31 per cent of the older population would be inside the boundary and hence eligible (equivalent to 3.4 million people in 2012, rising to an estimated 5 million in 2030 and 7 million by 2060).

Clearly, those inside the boundary represent not only a key target group but also a large segment of the PCSB market overall, and thus we can see why it is crucial that PCSBs be treated favourably for means-testing purposes if they are to encourage saving among this large sub-group.

We have not analysed the income-asset distribution of pre-65 adult age groups aged say 35 and over. Many will be bringing up families, paying off mortgages and therefore may not have much spare income. Because they are inexpensive and engaging, PCSBs should arguably be more attractive, affordable and engaging than, say, an expensive insurance product to this group also.

Because PCSBs are so simple, potentially new markets could also evolve among more vulnerable groups such as the economically inactive (this could include full-time carers, for example), people with no private or occupational pension arrangements, or the disabled, but we do not analyse this possibility any further here.

To summarise, given future increases in the older population and life expectancy, our assumption of around 12.6 million bond purchasers does not seem unreasonable in the circumstances, as long as people are drawn from a broad age range of backgrounds and not just the poorest.

${ }^{20}$ ELSA (2012). 


\section{Practical considerations}

If PCSBs are introduced there are three key practical issues to consider. These are first defining an event or events that would unlock access to individual funds, second the investment strategy underpinning the fund, and third the capacity and know-how to set up and administer PCSBs relatively inexpensively and efficiently.

As PCSBs are predicated on care being assessed by a responsible authority (currently local authorities), this suggests that a universal system of portable assessments would be a useful and necessary part of the scheme as set out in the Care Act (2014).

Access to the accumulated fund could also be triggered by eligibility for certain welfare benefits such as Attendance Allowance, which is a universal tax-free benefit to help with personal care for those who are aged 65 or over.

It should be noted that the Attendance Allowance is paid at a lower needs threshold than social care and thus may result in earlier access than a formal local authority care assessment leading to domiciliary or institutional care.

It can be argued that the earlier access is allowed to the fund the more it could be used to pay for preventative measures, for example, home adaptations or assisted-living technologies, which in turn may prevent care needs escalating as quickly.

Another type of event that could trigger access could be the onset of a critical illness. If someone is diagnosed with a serious illness that may be expected to shorten their lives, it could be appropriate to allow them to use their fund to improve the quality of their remaining life, especially if they have no dependants.

An altogether different approach would be to define a set of "eligible purchases", for example, a named home carer, care in a residential home, and/or approved home adaptations. This would require radically different administrative arrangements to any trigger-based approach, and these have not been considered or modelled in any detail here.

Because a proportion of the benefits is likely to be paid out in the form of death benefits to the next generation, this would boost their inheritance. Although the individual sums may be small, this may not be a bad thing as they could still help to pay for the immediate costs of death such as a funeral. On the other hand, larger estates may trigger liability for inheritance tax.

A second practical consideration is how the money is used by the state, for example, to fund the deficit or reduce the national debt. We believe there may also be scope to invest in a social enterprise that would promote the creation of social care infrastructure and/or improve the efficiency of the delivery of care.

The third issue to consider is the administration. Although NS\&I has been administering Premium Bonds since 1956 and is a trusted brand, PCSBs could be run by any organisation with the necessary experience and expertise. If thought desirable, administration could also be split between fund management and retail aspects.

From our enquiries, we know that all NS\&I products, including Premium Bonds, operate off the same technical platform. We further understand that NS\&I could replicate PCSBs if it were cloned on the same platform relatively easily. The implementation challenge would be the degree of change from the existing specification, and the enabling legislation that went with it.

The administrative cost of Premium Bonds is low mainly because NS\&I do not have a sophisticated retail arm and are also cost effective by commercial standards. According to NS\&I accounts, for each $£ 100$ billion of stock, it costs $£ 170$ million per year to run the 
operation, and therefore, a fund of $£ 60$ billion would cost around $£ 102$ million to administer; however, this ignores potential additional costs.

About $£ 2$ million to $£ 3$ million is spent on Premium Bond marketing each year against sales of $£ 8$ billion. Launching PCSBs, however, is a different proposition because any organisation would be starting from scratch. This would include building awareness of the new brand and product, promoting an understanding of the product itself, engendering confidence in the service proposition, and, critically, building an emotionally positive sense of customer loyalty.

In addition to marketing, there would be the costs of managing the assets, and providing people with statements, answering queries, regulatory costs, etc. There is also the administrative cost of paying claims, which would depend on factors such as the triggering system and whether pay-outs are in lump sums or instalments.

Distributional costs will vary according to the type and number of channels. The least costly are telephone or online sales and then by post. Third-party distribution (e.g. Post Office) would be more expensive, but at the same time, it would add reach. Finally, more innovative channels could also be considered such as through the workplace or employer

\section{Conclusions}

PCSBs are a suggested new way of saving for social care in old age. U.K. experience to date suggests that insurance products for long-term care will be expensive and not generally suited to everyone, even with the cap on care costs in place.

Although PCSBs, like insurance, pay out on the triggering of care needs, they have the additional attraction of producing substantial prize money that is tax free. In addition, unlike insurance premiums, unused bonds pass into a person's estate and are only subject to inheritance tax.

PCSBs are also inexpensive and can be bought in large amounts or small nominal units at any time. Unlike insurance premiums, their value is not linked in any way to the cost of care or the future funding gap faced by individuals, or to the risk of needing care.

Instead, they should be regarded as a contribution to future care costs and not a financial panacea as such. Because of the prize money, the negative prospect of money being locked up for a long period is reduced. This makes them more flexible and a good choice for those on a low income or with minimal assets. However, for the public to have full trust in them, it is important that government does not vary the rules by, for instance, arbitrarily tightening the eligibility rules for accessing the fund.

Purchasers will include people who would not be in a position to draw down equity from their homes or be able to afford regular insurance premiums for full-care costs or have substantial occupational pensions as sources of extra income. This group will include new types of saver such as those who had assumed their care costs would be met by the state.

We also saw that PCSBs are simple and likely to be very inexpensive to administer. The U.K. has considerable experience of running such schemes based on Premium Bonds, which have existed for over 50 years, are the U.K.'s single largest savings vehicle and are administratively efficient.

This is not, however, to underestimate the challenge of setting up a new system or the substantial marketing costs that would be entailed. Although people are used to lottery-style products and Premium Bonds in particular, PCSBs will require careful introduction including a clear understanding of how they will work in practice. 
An important strategic issue is how and whether the state profits from PCSBs through reduced expenditure on social care. If PCSBs are to succeed it will be necessary to convince potential customers that they are not saving for something to pay for things that the state would otherwise pay for.

This will depend on whether PCSBs would replace equivalent expenditure on social care, aside from funeral payments, in which case the state and hence the taxpayer benefits and not the individual. Such a rule change would be easy to implement, but future governments must resist changing the rules for the public to be convinced.

In our view there are further advantages from exempting PCSBs because it sends a clear signal that the state is concerned that people should save for social care by producing a lowcost, affordable product that the state would not then claw back through the means test.

The trigger mechanisms for PCSBs are important, and in so far as it is possible, these should be independent of future government policy (e.g. changes to the assessment process). One of the downsides of using Attendance Allowance, for example, is that a future government may decide to change or withdraw it.

We also saw that if people died without triggering payment, then the fund could save public money in death grants, and any balance remaining would pass to a person's estate. Average funeral costs vary enormously from around $£ 2,000$ upwards, but the money released in death benefits could help families and make modest reductions in welfare payments.

Getting the balance right between benefits taken while alive and after death is therefore a key feature of this product. If benefits are taken too early, the fund may not have accumulated sufficiently to make an impact, whereas if they are taken too late, part of their objective will have been wasted.

As we have stated, launching the product will be a significant undertaking, but as Premium Bonds have shown, the probability of success is high. If some of the fund is to be re-invested in the wider care economy, it will be important to ensure a good return by investing in the most profitable areas.

As with any new savings product, there is bound to be some effect on the wider savings industry. In general, however, we believe this to be relatively small for the reasons previously given (e.g. it will tend to attract new savers who do not have regular savings habits and the money involved is relatively small).

There could be competition with lottery expenditure as these are bought to some extent by similar people. As we have argued, however, the products are not identical and the motivation for purchasing lottery tickets only partially overlaps with PCSBs. The chances of winning a lottery prize are lower but the prizes are higher, but in addition, lottery stakes are non-returnable.

Limits on how much money could be held by a single individual in PCSBs before being subject to taxation could be needed just as there are limits on Premium Bond holdings. If the death benefits are tax free, for example, PCSBs could become an attractive way of sheltering wealth.

We believe, however, that this could be easily managed by linking fund size in some way to the Dilnot cap. There may also need to be limits on the amounts that can be purchased in one year to avert possible tax avoidance through asset switching. There is evidence that an annual allowance could be used to good marketing effect as with ISAs (now called NISAs), that is, a "use it or lose it" offer.

Conversely, there is a strong argument that states the fund would build more quickly if lump sum deposits were encouraged, for example, in the form of bequests or pension lump 
sums. A further suggestion to encourage large fund sizes is that they could be protected for inheritance tax purposes up to the value of the cap.

We also argued that PCSBs are a good strategic fit with other types of savings and sources of wealth. An example of this is realising equity from homes, which can serve several purposes such as providing income enhancement, purchasing long-term care insurance, or buying point of need products such as immediate needs annuities. However, we also saw that this option is not open to all.

Finally, it must be emphasised that PCSBs would not contribute significantly to social care costs for some years, but would build up over time. Since life expectancy and the number of older people is expected to increase in coming decades, we view this as part of a long-term solution to a long-term problem and only one of several financial building blocks.

Pension reforms already under way will help over time, but it is worth pointing out that pensions are also currently treated more unfavourably than assets in the means test, with those entering care losing state support pound for pound. Alternative arrangements to the social care means test and how it could be reformed more widely to deal with these and other issues are discussed in Mayhew et al. and Mayhew and O'Leary. ${ }^{21}$

The issue of how to fund social care in future years is near the top of the Government's agenda, but it has proven difficult to identify a single or short-term solution. However, it is equally clear that successive governments do not believe that the taxpayer should pay the whole bill.

In conclusion, the ideas in this paper are a contribution to the debate on the question of funding care. They have been widely discussed as part of the process of reforming social care and have been presented to ministers, care representatives, local authorities, policymakers and the personal finance industry.

The reaction has been universally positive but it is important to be realistic about what is possible as with any new scheme, including any enabling legislation required. The next two years or so will be very important in this regard.

\section{Acknowledgements}

The authors are grateful to the International Longevity Centre U.K. for its help and support in launching PCSBs in 2013 and beyond and for the ideas and refinements suggested by experts and stakeholders in the field. The paper has also benefited from discussion with the personal finance industry and National Savings and Investments (NS\&I). However, all views expressed are those of the authors.

\section{References}

Commission on Funding of Care and Support (2011) 'Fairer care funding-The Report of the Commission on Funding of Care and Support', from www.dilnotcommission.dh.gov.uk/our-report/, accessed 14 August 2014.

Department of Health (2013) 'Social care funding reform impact assessment', from www.parliament.uk/documents/ impact-assessments/IA13-14C.pdf, accessed 14 August 2014.

Douglas, A. (2000) British Charitable Gambling 1956-1994, Towards a National Lottery, London: Bloomsbury Publishing.

ELSA (2012) 'English Longitudial Study of Ageing', Wave 5, from http://discover.ukdataservice.ac.uk/series/ $? s n=200011$, accessed 21 August 2014 .

\footnotetext{
${ }^{21}$ Mayhew et al. (2010); Mayhew and O’Leary (2014).
} 
686

Royal Commission on Long Term Care (1999) With Respect to Old Age: Long Term Care-Rights and Responsibilities, HMG Cm 4192-1, London: The Stationery Office.

House of Lords-Select Committee on Public Service and Demographic Change (2013) 'Ready for ageing? - First Report', London: The Stationary Office Limited, from http://www.publications.parliament.uk/pa/ld201213/ ldselect/ldpublic/140/140.pdf, accessed 14 August 2014.

Institute and Faculty of Actuaries (2014) 'How pensions can help meet consumer needs under the new social care regime: An overview' from www.actuaries.org.uk/research-and-resources/documents/how-pensions-can-meetconsumer-needs-under-new-social-care-regime-f, accessed 14 August 2014.

Karlsson, M., Mayhew, L., Plumb, R. and Rickayzen, B. (2006) 'Future costs for long-term care: Cost projections for long-term care for older people in the United Kingdom', Health Policy 75(2): 187-213.

Karlsson, M., Mayhew, L. and Rickayzen, B. (2007) 'Long term care financing in four OECD countries: fiscal burden and distributive effects', Health Policy 80(1): 107-134.

Kearney, M.S. (2005) 'State lotteries and consumer behavior', Journal of Public Economics 89(11-12): 2269-2299.

Kearney, M.S., Tufano, P., Guryan, J. and Hurst, E. (2010) Making savers winners: an overview of prize-linked savings products, NBER Working Paper No. 16433, Cambridge, MA: National Bureau of Economic Research, from www.nber.org/papers/w16433, accessed 14 August 2014.

Laitner, J. (1999) 'Means-tested public assistance and the demand for state lottery tickets', Economic Dynamics 2(1): 273-290.

Mayhew, L., Karlsson, M. and Rickayzen, B. (2010) 'The role of private finance in paying for long term care', The Economic Journal 120(548): F478-F504.

Mayhew, L. and Rickayzen, B. (2012) 'The ageing population: Crunch time for government reforms', Economic Affairs 32(2): 96-100.

Mayhew, L. and O'Leary, D. (2014) Unlocking the Potential. London: DEMOS, from http://www.demos.co.uk/files/ Unlocking_potential_-_web.pdf?1393180449, accessed 14 August 2014.

Tufano, P. (2008) 'Savings whilst gambling: An empirical analysis of U.K. premium bonds', American Economic Review Papers and Proceedings 98(2): 321-326.

Tufano, P., Maynard, N. and Emmanuel De, J. 'Neve' (2008) Consumer demand for prize-linked savings: a preliminary analysis, Harvard Business School Working Paper 08-061, from www.hbs.edu/research/pdf/ 08-061.pdf, accessed 14 August 2014.

Rickayzen, B. and Walsh, R. (2002) 'A multi state model of disability for the UK: Implications for need for long term care for the elderly', British Actuarial Journal 8(2): 341-392.

Rickayzen, B. (2007) An analysis of disability-linked annuities, Actuarial Research Paper No. 180, London: Cass Business School.

\section{Mathematical Appendix}

Basics

Let us assume that we are working in real terms, that is, that the amounts are adjusted to take into account price inflation (or assume that inflation is 0 per cent).

Define the real investment return earned on the fund as $i$ per cent.

Define the amount of return used to fund prizes as $p$ per cent.

Define the amount of return retained by the fund as $(i-p)$ per cent $=r$ per cent.

Assume that, at the start of each year, each person aged 18 and over purchases a fixed number of bonds, $b$ (where each bond is valued as $£ 1$ in terms of the initial year).

Before we reach a steady state, for a person still alive and not requiring care at time $t$ (but before purchasing the bonds at time $t$ ), their fund will have accumulated to:

$$
A_{t}=b \frac{(1+r)^{t}-1}{d} \text { where } d=\frac{r}{1+r}
$$


When a steady state is reached, then the age of each person who is still healthy will also determine the length of time spent in the state, that is, if a person has current age, $c$, then they will have spent $c$ - 18 years in the fund. Redefining the accumulation of assets slightly so as to allow for this 18-year adjustment, we can specify the fund held for a person aged $c$ as:

$$
A_{c}=b \frac{(1+r)^{c-18}-1}{d} .
$$

Once the steady state has been reached, we can calculate the value of the total fund, $F$, by:

$$
F=\sum_{c=18}^{110} A_{c} l_{c},
$$

where $l_{c}$ is the number of people in the fund at age $c$.

\section{Cash flows}

We will assume that $x$ per cent of people who are aged 65 and above require the benefit due to sickness and we will assume that people who require this sickness benefit require it $m$ years before they die. We will also assume that both deaths and sickness occur on average half-way through the year. Finally, it should be noted that the benefit is the return of the fund and therefore it does not matter whether the person received the benefit due to death or sickness.

Define:

$l_{c} \quad$ as the number of people who are currently active at age $c$, that is, they are alive and have not taken benefits due to illness

$a_{c} \quad$ as the number of people who die at age $c$

$d_{c} \quad$ as the number of people who die at age $c$ in a healthy state

$s_{c} \quad$ as the number of people who fall sick at age $c$

$\Omega \quad$ as the maximum age at death

We therefore have:

$$
l_{c+1}=l_{c}-d_{c}-s_{c} .
$$

For ages up to 65 , that is, $c<65$, then the benefit outgo will be the probability of death only. We therefore have $q_{c}=d_{c} / l_{c}=a_{c} / l_{c}$, where $q_{c}$ is the probability of the person leaving the fund and receiving a benefit.

For age 65 and over, we have to take into account both sickness and death. For the number who become sick at age $c$ we have:

$$
s_{c}=x \times a_{c+m} .
$$

For age 65 to $65+m$, the number of deaths remains as before, that is, $d_{c}=a_{c}$, and therefore the number of people claiming benefits is $d_{c}+s_{c}$.

For age $65+m$ onwards, the number of deaths that are triggering a benefit is now $d_{c}=(1-x) a_{c}$, that is, we have ignored the deaths of people who had previously fallen ill and taken the benefit $m$ years ago. 
If we explicitly define $s_{c}=0$ for $c<65$ and $c>\Omega-m$, then for all ages the probability of a person taking a benefit over the year is:

$$
q_{c}=\frac{d_{c}+s_{c}}{l_{c}}
$$

\section{Value of benefits}

If we assume that the fund accumulates over the half year before the benefit payment is triggered, then the value of benefits for the population aged $c$ is:

$$
B_{c}=\left(A_{c}+b\right) \times(1+i)^{0.5} \times \frac{r}{i} \times l_{c} q_{c}
$$

and hence the total value of benefits is:

$$
B=\sum_{x=18}^{\Omega} B_{x}
$$

\section{Value of prizes}

The amount that can be paid out in prizes is the amount of return earmarked for prizes, that is, from the fund that is still active at the end of the year plus the return over the half year from the part of the fund that was paid out in benefits.

$$
P=\sum_{c=18}^{\Omega}\left\{\left(A_{c}+b\right) \times p \times\left(1-q_{c}\right) l_{c}+\left(A_{c}+b\right) \times\left[(1+i)^{0.5}-1\right] \times \frac{p}{i} \times q_{c} l_{c}\right\} .
$$

\section{Impact of simplifying assumptions}

\section{Timing of purchases of bonds}

We have assumed that bonds are purchased at the start of the year. A more realistic assumption would be that they are purchased throughout the year. This means that the value of the fund will be lower as the number of bonds purchased will be lower each year as, of course, people will stop buying the bond when they die or need care during the year, and in addition, there will be less time for the bond to accumulate interest. Having a lower fund will mean both lower benefits and prizes than currently assumed.

\section{Prizes}

As noted above, we would have a smaller prize fund if bonds were assumed to be purchased throughout the year. In addition, if we assume that prizes are paid out each month rather than at the end of the year, then there will be less time for the prize fund to accumulate. As the prizes are cost-neutral to the fund this is not a problem, but this would make the bonds less attractive to purchasers of bonds if the values are slightly lower than calculated here. 


\section{Inflation}

Thus far we have assumed no inflation. This makes calculations and results much easier when we state the value of the fund in, say, 80 years time, as we do not want to have inflation distorting the value. Introducing inflation is not a problem as we can simply use real rates of return in most of our calculations.

We have assumed that PCSBs will have a nominal value of $£ 1$ in perpetuity. This may work against the scheme if it results in purchasers not increasing the number of bonds they buy over time (i.e. they only ever buy $£ 100$ worth of bonds a year). An alternative would be a scheme in which purchasers buy "a bond" at whatever the currently denominated value is at the time.

In the calculations, the main difference comes when valuing the amount of return that comes from the bonds that are cashed in to pay for the benefits, as we have to determine the amount of return that is retained in the fund and that which is put into the prize fund. When there was no inflation we could use a simple ratio.

Now let us introduce the idea of a nominal return (nom) and inflation (in). Then to get our real return, $i$, defined earlier, we have:

$$
(1+i)=\frac{(1+n o m)}{(1+i n)} .
$$

For the return made on bonds that are cashed in to pay benefits, we split the return so that the fund retained $(r / i)$ per cent and the prize fund received $(p / i)$ per cent. To make sure that the fund is not eroded by inflation, the inflation part of the nominal return needs to be retained by the fund. The above values therefore become (nom-p/nom) per cent and the prize fund receives (p/nom) per cent.

\section{Distribution of prize winners}

The table below shows two likelihoods of winning. The first one is the probability that a winning ticket will come from a particular age in the population. The second is the likelihood of a particular person who does not die during the year of getting a winning ticket compared with an 18-year-old, that is, a value of 4 means they are four times more likely to win than an 18-year-old.

\begin{tabular}{lcc}
\hline Age & $\begin{array}{c}\text { Probability a winning ticket is } \\
\text { from this age }(\%)\end{array}$ & $\begin{array}{c}\text { How likely a person of this age is to win compared with an } \\
\text { 18 year old (assuming that neither dies) }\end{array}$ \\
\hline 18 & 0.03 & 1.00 \\
19 & 0.05 & 2.02 \\
20 & 0.08 & 3.06 \\
21 & 0.11 & 4.12 \\
22 & 0.14 & 5.20 \\
23 & 0.17 & 6.31 \\
24 & 0.20 & 7.43 \\
25 & 0.23 & 8.58 \\
26 & 0.26 & 9.75 \\
27 & 0.29 & 10.95 \\
28 & 0.33 & 12.17 \\
29 & 0.36 & 13.41 \\
30 & 0.39 & 14.68 \\
\hline
\end{tabular}


The Geneva Papers on Risk and Insurance-Issues and Practice 690

\begin{tabular}{|c|c|c|}
\hline Age & $\begin{array}{l}\text { Probability a winning ticket is } \\
\text { from this age }(\%)\end{array}$ & $\begin{array}{l}\text { How likely a person of this age is to win compared with an } \\
18 \text { year old (assuming that neither dies) }\end{array}$ \\
\hline 31 & 0.43 & 15.97 \\
\hline 32 & 0.46 & 17.29 \\
\hline 33 & 0.50 & 18.64 \\
\hline 34 & 0.54 & 20.01 \\
\hline 35 & 0.57 & 21.41 \\
\hline 36 & 0.61 & 22.84 \\
\hline 37 & 0.65 & 24.30 \\
\hline 38 & 0.69 & 25.78 \\
\hline 39 & 0.73 & 27.30 \\
\hline 40 & 0.77 & 28.84 \\
\hline 41 & 0.81 & 30.42 \\
\hline 42 & 0.85 & 32.03 \\
\hline 43 & 0.90 & 33.67 \\
\hline 44 & 0.94 & 35.34 \\
\hline 45 & 0.98 & 37.05 \\
\hline 46 & 1.03 & 38.79 \\
\hline 47 & 1.07 & 40.57 \\
\hline 48 & 1.12 & 42.38 \\
\hline 49 & 1.17 & 44.23 \\
\hline 50 & 1.21 & 46.11 \\
\hline 51 & 1.26 & 48.03 \\
\hline 52 & 1.31 & 49.99 \\
\hline 53 & 1.36 & 51.99 \\
\hline 54 & 1.41 & 54.03 \\
\hline 55 & 1.46 & 56.11 \\
\hline 56 & 1.51 & 58.24 \\
\hline 57 & 1.56 & 60.40 \\
\hline 58 & 1.61 & 62.61 \\
\hline 59 & 1.66 & 64.86 \\
\hline 60 & 1.71 & 67.16 \\
\hline 61 & 1.76 & 69.50 \\
\hline 62 & 1.81 & 71.89 \\
\hline 63 & 1.86 & 74.33 \\
\hline 64 & 1.90 & 76.82 \\
\hline 65 & 1.95 & 79.35 \\
\hline 66 & 2.00 & 81.94 \\
\hline 67 & 2.04 & 84.58 \\
\hline 68 & 2.08 & 87.27 \\
\hline 69 & 2.12 & 90.02 \\
\hline 70 & 2.16 & 92.82 \\
\hline 71 & 2.19 & 95.67 \\
\hline 72 & 2.22 & 98.59 \\
\hline 73 & 2.25 & 101.56 \\
\hline 74 & 2.27 & 104.59 \\
\hline 75 & 2.29 & 107.68 \\
\hline 76 & 2.30 & 110.83 \\
\hline 77 & 2.30 & 114.05 \\
\hline 78 & 2.29 & 117.33 \\
\hline 79 & 2.28 & 120.68 \\
\hline 80 & 2.25 & 124.09 \\
\hline 81 & 2.21 & 127.57 \\
\hline 82 & 2.15 & 131.13 \\
\hline 83 & 2.09 & 134.75 \\
\hline 84 & 2.01 & 138.44 \\
\hline 85 & 1.92 & 142.21 \\
\hline 86 & 1.81 & 146.06 \\
\hline
\end{tabular}




\begin{tabular}{|c|c|c|}
\hline Age & $\begin{array}{l}\text { Probability a winning ticket is } \\
\text { from this age (\%) }\end{array}$ & $\begin{array}{c}\text { How likely a person of this age is to win compared with an } \\
18 \text { year old (assuming that neither dies) }\end{array}$ \\
\hline 87 & 1.69 & 149.98 \\
\hline 88 & 1.56 & 153.98 \\
\hline 89 & 1.42 & 158.06 \\
\hline 90 & 1.27 & 162.22 \\
\hline 91 & 1.13 & 166.46 \\
\hline 92 & 1.00 & 170.79 \\
\hline 93 & 0.85 & 175.21 \\
\hline 94 & 0.72 & 179.71 \\
\hline 95 & 0.59 & 184.31 \\
\hline 96 & 0.47 & 188.99 \\
\hline 97 & 0.37 & 193.77 \\
\hline 98 & 0.28 & 198.65 \\
\hline 99 & 0.21 & 203.62 \\
\hline 100 & 0.15 & 208.69 \\
\hline 101 & 0.10 & 213.87 \\
\hline 102 & 0.07 & 219.14 \\
\hline 103 & 0.05 & 224.53 \\
\hline 104 & 0.03 & 230.02 \\
\hline 105 & 0.02 & 235.62 \\
\hline 106 & 0.01 & 241.33 \\
\hline 107 & 0.01 & 247.16 \\
\hline 108 & 0.00 & 253.10 \\
\hline 109 & 0.00 & 259.16 \\
\hline
\end{tabular}

\section{Effect on fund of changes to the percentage needing care}

If the proportion of people needing care increases, then less money is available to pay for funeral expenses and vice versa. However, the balance of these two effects has relatively little impact on the size of the fund, as shown in the table below.

This shows the size of the fund once matured according to different levels of bond purchases and the percentage of people drawing down the money to pay for social care. Units are billions of pounds.

The effect of a greater percentage of investors triggering care is to bring forward the outflow of funds and thus reduce slightly the total value of the fund. As can be seen, the resulting change is negligible even at high percentages.

\begin{tabular}{lrrrrr}
\hline \multirow{2}{*}{ Bonds purchased p.a. } & \multicolumn{5}{c}{ \% needing care } \\
\cline { 2 - 5 } & 10 & 20 & 30 & 40 & 50 \\
\hline 50 & 35.4 & 35.2 & 34.9 & 34.6 & 34.4 \\
100 & 70.8 & 70.3 & 69.8 & 69.3 & 68.8 \\
150 & 106.2 & 105.4 & 104.7 & 103.9 & 103.2 \\
200 & 141.6 & 140.6 & 139.6 & 138.6 & 137.6 \\
\hline
\end{tabular}

Assumed take-up in this example: 25 per cent (cell values $£$ billion). 


\section{About the Authors}

Les Mayhew is Professor of Statistics at Cass Business School, London in the Faculty of Actuarial Science and Insurance. He is an Honorary Fellow of the Institute and Faculty for Actuaries and a member of the Royal Economic Society. He is a former senior civil servant and a member of the Office for National Statistics expert panel that advises on population projections. He is widely published and twice winner of the Cass research prize.

David Smith is a lecturer in Actuarial Science at Cass Business School, City University, London.

This work is licensed under a Creative Commons Attribution 3.0 Unported

License. The images or other third party material in this article are included in the article's Creative Commons license, unless indicated otherwise in the credit line; if the material is not included under the Creative Commons license, users will need to obtain permission from the license holder to reproduce the material. To view a copy of this license, visit http://creativecommons.org/licenses/by/3.0/ 